\title{
MARATONAS DE VÍDEO E A NOVA FORMA DOMINANTE DE SE CONSUMIR E PRODUZIR SÉRIES DE TELEVISÃO
}

\author{
Humberto de Campos Rezende \& João Victor Boechat Gomide
}

\begin{abstract}
RESUMo
Esse artigo analisa o binge watching, ou maratona de mídia, e os estudos de compulsão no consumo de mídia televisiva, e discute como a popularização desse comportamento vem modificando o modelo de se produzir conteúdo para televisão. Esse fenômeno começou timidamente com o videocassete e algumas programações especiais de canais de televisão a cabo, e hoje acontece de forma explosiva na transmissão de vídeo pela internet, provocando uma nova forma de produzir e consumir a cultura visual, em telas de televisão ou monitores de computador, smartphones e tablets. O Netflix e o YouTube são os principais expoentes na produção e distribuição de conteúdo voltado para o engajamento da audiência com aspectos viciantes, em um novo paradigma de distribuição da programação, por demandas individuais do espectador. Isso tem impactado especialmente na produção de séries da teledramaturgia, onde a narrativa se reestrutura com as novas perspectivas abertas pela tecnologia, buscando diferentes estratégias, tanto para a televisão broadcast quanto para a distribuição ponto a ponto, em ressonância com esse comportamento contemporâneo, como é abordado nesse trabalho.
\end{abstract}

\section{Palavras-Chave}

Binge watching; maratonas de vídeo; narratologia; séries de televisão; televisão pela internet

\begin{abstract}
This article examines binge watching, also known as media marathoning, and related studies in television media consumption, and discusses how the popularization of such behavior has been modifying the model of producing television content. This phenomenon began timidly with the VCR and some special programming of cable television channels, and today happens explosively in the streaming of video over the internet, provoking a new way to produce and consume visual culture, in television or computer, smartphones and tablets displays. Netflix and YouTube are the leading exponents in the production and distribution of audience-driven content with binging features in a new programming distribution paradigm, by individual viewer demands. This has especially impacted the production of TV dramaturgy series, where the narrative is restructured with the new perspectives opened by technology, seeking different strategies, both for broadcast television and for pear-to-pear distribution, in resonance with this contemporary behavior, as it is presented in this work.
\end{abstract}

\section{KEYWORDS}

Binge watching; internet television; narratology; TV series; video marathoning 


\section{MARATONAS E ASSISTÊNCA COMPULSIVA DE VÍDEO}

Nos últimos anos se tornou possível assistir a temporadas inteiras de uma série de televisão sem interrupções comerciais, praticamente em qualquer plataforma (tela), com a tecnologia de distribuição de vídeos por transmissão na internet. Isso facilitou o acesso a títulos em escala praticamente mundial, incluindo lançamentos, seja pelos serviços pagos, como Netflix, Amazon ou YouTube, ou de forma ilegal, como nos arquivos do tipo torrent. Essa novidade difundiu o hábito do consumo seguido de vários episódios das séries de uma só vez, em um fenômeno que recebeu o nome de binge watching, que ainda não encontra um termo equivalente em português.

Essa forma de consumo, que existia desde a popularização dos videocassetes, a partir do final dos anos 1970, vem ganhando adeptos e se tornando cada vez mais comum, adquirindo um status de comportamento. Como consequência, tem se tornado uma prática comum das produtoras de séries televisivas lançarem todos os episódios de uma temporada de uma só vez. Isso foi realizado primeiramente pelos canais de televisão da internet, nos serviços de vídeo sob demanda (vídeo on demand, VOD), com início em 2013 pelo Netflix, e, mais recentemente, pelos canais de televisão broadcast, nos seus serviços pagos da internet, antes de disponibilizar cada episódio na programação tradicional.

Perks dá preferência ao termo media marathoning. Segundo ela, o conceito de compulsão (binge) traz em si uma conotação negativa, a ideia de uma ação perniciosa ao indivíduo, e que foi provavelmente alcunhado pelos jornalistas ligados ao entretenimento, pela reação negativa a essa nova forma de se assistir TV. Para a autora, esses jornalistas têm como base retórica a noção de que os espectadores são "como insensíveis e irracionais, correndo atrás daquilo que poderia ser uma experiência de mídia mais agradável, e prazerosa" (Perks, 2014, p. 11).

Apesar da possível conotação negativa do termo, o termo binge watching será utilizado nesse artigo, por ser mais empregado na literatura. $O$ termo também é mantido em inglês por não haver ainda uma referência consolidada do mesmo em português. Uma sugestão é utilizar o termo maratona de vídeos. Por ser algo recentemente identificado como objeto de atenção, foram publicados poucos estudos científicos até agora, como pode ser constatado em uma busca por artigos científicos com esse termo.

Perks busca contextualizar esse comportamento em seu livro, para qualquer tipo de mídia, e afirma que essa forma de se relacionar com o objeto de mídia, seja ele escrito ou audiovisual, está ligado a três variáveis essenciais: tecnologias de distribuição, comportamento ativo e aumento da complexidade no conteúdo da mídia de entretenimento:

Ao controlar o ritmo da jornada narrativa e focar no mundo único da história, os maratonistas podem maximizar as recompensas emocionais e cognitivas nas suas experiências de mídia. O engajamento focado dos maratonistas com seus textos promove memórias diegéticas mais fortes que realça a a conectividade cognitiva e emocional ao mundo da história. O investimento afetivo do leitor (maratonista) transforma os personagens 
em pseudo-avatares, borrando as linhas entre leitor e personagem na sua jornada coordenada. (Perks, 2014, p. 12)

A tecnologia de distribuição vem, a partir das últimas décadas do século XX, apresentando novas alternativas, que representam modificações profundas no acesso do espectador ao conteúdo, antes apenas encontrado nas salas de cinema e nos canais de televisão broadcast. Essas mudanças começaram com os canais de televisão a cabo especializados, a distribuição das fitas de videocassete, dos DVDs, discos blue-rays, e, mais recentemente, com a transmissão de vídeo pela internet, possível apenas com a internet de banda larga, e têm popularizado e transformado toda a forma de se relacionar com o texto audiovisual, com consequências também na própria produção de conteúdo.

Em um dos estudos pioneiros sobre o fenômeno, Jenkins (2012) parte da observação de grupos de consumidores de programas de TV e como eles se organizavam e como essa forma de consumir influenciava a produção de conteúdo. Uma das colaboradoras da pesquisa seminal de Jenkins, Meg Garret, chama a atenção para um dos aspectos desse novo fenômeno:

usando o Videocassete e uma rede de fãs pré-existentes, o espectador de TV está livre das limitações da programação local. Quer assistir ao B7ou Sandbaggers ou Red Dwarf, mas sua estação ignora suas cartas? Pergunte por ai e logo terá sua própria cópia e você pode ignorar a estupidez do diretor de programação. (Jenkins, 2012, p. 72)

Ao nos afastarmos do controle do diretor de programação nos sistemas de broadcast $T V$, permitindo o próprio espectador ditar o ritmo de consumo da série, podemos dizer que o espectador tem a possibilidade de assistir de forma ininterrupta ou mesmo entrecortar, interromper a narrativa muito mais vezes do que ela seria pela publicidade normal. Isso pode acontecer por pausas, para acessar informações pertinentes à série ou realizar tarefas totalmente alheias em outras telas, como mensagens, Facebook e outras.

A forma de consumo de uma série de forma compulsiva, ou como uma maratona, pode estar conectada não somente ao acesso ilimitado ao conteúdo, como nos serviços VOD, e de forma ininterrupta, mas à possibilidade de interrupção, seja em qualquer momento da trama, favorecido pelo universo de outros campos de significados, ou simplesmente pela interconectividade que o meio de consumo permite ao usuário. Uma pesquisa encomendada pela empresa Netflix, em 2013, identificou que o binge watching é a nova forma comum de se assistir TV. Ela constatou que $73 \%$ dos espectadores que participaram da pesquisa, tinham o hábito de consumir de 2 a 6 episódios de um mesmo programa ininterruptamente (Netflix, 2013).

Na próxima seção, será analisado o primeiro aspecto influenciador das maratonas de vídeo, isto é, as tecnologias de distribuição na internet, para contextualizar essas novidades dentro desse estudo, sem aprofundar em questões técnicas. Em seguida, o comportamento ativo do espectador será debatido, com as suas consequências nas 
associações em grupo e no binge watching. Na quarta seção, será discutido o aumento da complexidade no conteúdo da mídia de entretenimento e as mudanças no desenvolvimento de roteiros, na produção e na distribuição de séries televisivas, e quais são as tendências. Na última seção, apresentamos as conclusões da análise desse fenômeno, que apesar de não ser recente, se tornou dominante com a internet e a web.

\section{A DistribuiçÃo DE TELEVISÃo PELA INTERNET}

Em 1994, três anos antes do lançamento da televisão broadcast de alta definição (HDTV), o canal de televisão ABC, dos Estados Unidos, começou a transmitir a ABC News pela internet. Um ano depois, o canal broadcast CBS, passou a adotar a mesma estratégia, com o CBS News, invertendo o planejamento existente de trazer a internet para a televisão por trazer a televisão para a internet (Huffingtonpost, 2015).

Nessa época, a recepção de vídeo pelo espectador era feita pelo modem de telefone, com uma velocidade de transmissão de dados que permitia uma resolução da imagem de vídeo de 320 por 240 pixels e metade da quantidade de quadros (frames) por segundo, bem abaixo do sinal da HDTV, que seria de 1920 por 1080 pixels, em 1997. A partir dos avanços tecnológicos, que permitiram aumentar a quantidade de dados transmitidos pela internet, novas tendências foram sendo criadas, implementadas e popularizadas, revolucionando a televisão na internet. Atualmente, todas as residências do Japão são conectadas à internet por fibra óptica, por exemplo, e a resolução de televisão $4 \mathrm{~K}$, de 4096 por 2160 pixels, é padrão nas transmissões de vídeo pela internet. Testes de transmissão do formato $8 \mathrm{~K}$, com vídeos de 7680 por 4320 pixels, via satélite e internet, vêm sendo realizados desde 2014 (Nakamura, 2015).

$\mathrm{Na}$ Suécia era possível, a partir de 2002, baixar longas metragens em poucos minutos, com velocidades inexistentes nos Estados Unidos, por exemplo, fazendo com que as locadoras físicas de videocassetes e DVDs se tornassem menos úteis (Grenouille, 2004). Essa realidade é diferente de praticamente todos os outros países nos dias de hoje, onde a velocidade de transmissão pela internet é muito menor. Por isso, a estratégia de transmitir o vídeo com resolução variável, se adaptada à largura de banda do receptor do espectador, é adotada e permite a transmissão da televisão pela internet em quase todo o mundo.

No Ocidente, as empresas de televisão na internet passaram, com a possibilidade de veicular vídeos de alta definição, a ser não somente um meio de distribuição, mas um meio produtor de conteúdo, com toda uma estrutura de consumo e de produção próprios e convergentes de vários outros meios. Atualmente, encontramos diferentes modalidades de serviços de televisão pela internet, seja fornecido por empresas de televisão, produtoras de cinema e de games, como a BBC Three, a Playstation Vue e a GloboPlay, seja por canais independentes com distribuição ponto a ponto, como Netflix, Amazon Video e YouTube.

O Netflix é uma referência na produção e distribuição de televisão para a internet, por seus serviços pioneiros na facilitação do acesso ao conteúdo audiovisual para os espectadores. Começou como uma empresa da internet que fornecia aluguéis de DVDs 
online, a partir de 1997, enviando a mídia para qualquer lugar dos Estados Unidos. Em 2007, ela passou a oferecer filmes por streaming para seus assinantes, e, em 2012, começou a produzir também conteúdo. Foi a primeira televisão da internet a receber nominações para o prêmio Emmy ${ }^{1}$, em 2013, com as séries House of Cards, Orange is the new black, e The Square. House of Cards recebeu três Primetime Emmy Awards naquele ano (Netflix, 2017).

A forma como o Netflix está se expandindo, atualmente presente em 119 países, com mais de 100 milhões de assinantes, fez com que o seu presidente, Reed Hasting, fizesse uma provocação em 2014, prevendo que a televisão broadcast desapareceria até 2030 (Digital TV Europe, 2014).

Empresas como, por exemplo, a Warner, lançou de uma vez os 10 episódios da temporada da série Angie, transmitindo-os por 25 horas e ganhando 1/3 de novos espectadores. A série Impastor, da Viacom, foi modificada quanto à sua estrutura narratológica para tentar atingir os binge watchers. A TV Globo tem lançado séries, que podem ser assistidas de uma só vez por streaming antes da exibição seriada em broadcast, no seu canal de internet Globo Play. Algumas empresas, como a CBS, estão buscando formas de serializar os anúncios para que o mesmo anúncio não seja mostrado várias vezes aos binge watchers, e tentam conectar os anúncios às histórias (Reuters, 2016).

Michael Wolff faz uma comparação na evolução da TV a cabo, que começou pela oferta dos serviços de transmissão por cabo, e a televisão na internet, que começou com a construção da rede de computadores:

o cabo começou em grande parte como a criação de empresas de infraestrutura, e depois se rendeu, ou sua programação se rendeu, para o bem ou para o mal, às empresas de entretenimento. A sensibilidade risível, de baixa renda e um tanto quanto esquisita nos primeiros anos do cabo se dedicou primeiro a transmitir o refugo e as propriedades menos lucrativas da televisão e a construir um novo mercado extraordinário para elas (por exemplo, a TV a cabo se transformou em uma forma reconhecível, mas distinta, de televisão). E obviamente, é isso que vai acontecer com a Netflix, a Amazon, o Yahoo, o Google e o Facebook. (Wolff, 2015, p. 158)

Os formatos de tempo tradicionais para a televisão, listados por Doc Comparato em seu livro (1998), são o de telefilme, que se aproxima do longa-metragem do cinema, e os formatos de 25 minutos e de 50 minutos, das telenovelas e séries, por exemplo, que possuem uma estrutura própria, entrecortada por interrupções comerciais e com "ganchos" ou situações cruciais, que têm como objetivo impedir que o público desligue a TV. Além da estrutura da história a ser contada, com os tempos e momentos de se criar uma conexão entre um bloco de conteúdo e outro, há uma outra gama de detalhes, como número de personagens, ambientes e cenários, que devem ser levados em consideração para a produção do conteúdo para a TV (Comparato, 1998, pp. 196-203).

' Emmy Awards é a principal premiação nos Estados Unidos para profissionais e programas de televisão de todo o mundo, realizado desde 1949. O Primetime distingue o conteúdo como reconhecimento pela excelência na programação televisiva. 
Essa lógica estrutural e dinâmica da televisão tradicional não necessariamente se reflete no conteúdo de vídeo da internet. Os formatos de conteúdo se multiplicam em estruturas temporais de meros segundos, até temporadas inteiras de 50 minutos por episódio, com várias formas de se contar uma história, como por exemplo a websérie Artistically Challenged, feita exclusivamente para o Instagram (@actheseries, s.d.).Presenciamos agora uma nova forma de distribuição, com as temporadas das séries sendo disponibilizadas com todos os seus episódios, no lançamento, que começou inicialmente com o Netflix e hoje é praticado por todos os canais de televisão produtores de séries, nos seus serviços pagos pela internet. As inserções de publicidade e a forma em que o faturamento da empresa se estrutura difere também da televisão tradicional, com diferentes modelos de negócio, como o número de acessos dos canais do YouTube ou as assinaturas do GloboPlay e do Netflix.

Apesar do comportamento ativo fora da tela, que é um elemento componente do binge watching, os formatos dos shows que provocam um engajamento não sofreram, por enquanto, grandes mudanças em relação à extensão dos episódios. O que está mudando é o ritmo da narrativa, para atender a uma audiência que assiste de duas a seis horas de uma série ininterruptamente.

Os programas continuam, mesmo lançados para video on demand, tendo a minutagem padrão da televisão, com 25 minutos ou 50 minutos cada episódio aproximadamente. Há também os telefilmes de 1 hora e 30 minutos. Porém, apesar do primeiro momento do vídeo na web ter permitido uma profusão de tamanhos de conteúdo, aqueles que mais provocam o binge watching continuam com os formatos e a duração temporal da televisão clássica. As possibilidades de interação com o objeto audiovisual dramático pode ser algo possível e fomentado via os serviços de streaming ou VOD, mas não é somente essa possibilidade de interação que atrai a audiência. "O Netflix está trazendo à programação, os valores e o comportamento da televisão - como a observação passiva - para telas que costumavam ser interativas e relacionadas à computação", afirma Wolff (2015, p. 87).

Apesar do desenvolvimento de roteiro para a televisão da internet sugerir que novas estruturas de conteúdo passam a ser relevantes, algumas práticas são comuns na indústria do entretenimento:

os criadores ainda são pagos para entregarem um certo número de episódios com uma duração pré-determinada, embora uma duração não ligada a intervalos comerciais. Por implicação, isso pode sugerir que a prática de scrip development desses criadores podem se manter alinhadas aos processos tradicionais discutidos posteriormente. Contudo, há evidências que sugerem que, nesse caso, o conteúdo do Netflix talvez tenha mais em comum com outros tipos de conteúdo online, tipo as webséries previamente mencionadas. (Taylor, 2015, p. 3) 


\section{BINGE WATCHING E O ESPECTADOR ATIVO}

A forma de se associar a um objeto audiovisual muda a partir do momento que o chefe de programação passa a ser substituído pelo acesso total da programação. Indo além da questão das horas passadas diante da tela da TV para caracterizar o binge watching, o termo se apresenta também como um fenômeno cultural e uma nova forma de associação de pessoas. A constituição de fandoms e o comportamento de escrutinar o universo das séries compõem o processo de se viciar em um texto-audiovisual. Os Fandoms, ou grupo de fãs de um determinado produto cultural, e a forma como esses grupos se organizam, contribuem para a compreensão do binge watching.

Ainda no início dos anos 1990, (Jenkins, 2012) demonstrava em sua pesquisa que o processo de ativismo ao se consumir um programa de TV era parte importante do engajamento com o objeto de consumo. Nesse contexto, M. Jenner afirma que o ambiente online, nas redes sociais, como Twitter, Facebook e outros, encorajam o comportamento típico de fã, tornando a participação uma atividade fácil (Jenner, 2015, p. 15).

Perks ressalva que a prática do media marathoning não necessariamente condiz com um comportamento exclusivo de fã, mas de um comportamento "fan-like" ou típico de fã, sobre a organização de fãs e as maratonas de mídia, fato que Jenner também aborda, com a descrição do engajamento dos não-fãs (Jenner, 2015, p. 12):

maratonistas frequentemente adotam as práticas e os comportamentos de fãs - frequentemente discutindo, pesquisando, e pensando sobre a história a qual se engajaram. Menos frequente, mas não menos importante, eles também forma rituais em relação ao enjagamento, memorializando suas identidades com compras relacionadas à mídia, empreendendo peregrinações aos sites santificados pelos fãs. (Perks, 2014, p. 54)

De um lado temos a disponibilidade tecnológica de acesso ao conteúdo, sem a intervenção no horário pelo diretor de programação, e do outro temos o incentivo do comportamento de fã para buscar detalhes da trama que escapam aos olhos menos incautos, ampliando a experiência de relacionamento com o produto de mídia, seja pelos antigos fandoms de bairro, que hoje se organizam também online, seja nas trocas de fitas, DVDs e, nos dias atuais, pelos processos de interação online em blogs, sites, fóruns e redes sociais. O que conecta esses dois lados é o texto, que participa com uma contribuição peculiar para o consumo desenfreado de mídia. O texto-audiovisual é o que permeia o acesso tecnológico e o comportamento de consumo.

Binge watching, como se depreende dessas observações, não é somente o ato de passar horas a fio, sem interrupções, consumindo um mesmo produto de mídia. A essas horas se deve adicionar o tempo gasto no processo de consumo "fora da tela", na construção do sentido, tanto em grupos, como os fandoms ou fóruns de discussão online, quanto no comportamento individual de buscar informações e mais detalhes do universo ficcional apresentado nas séries.

Podemos dizer que binge watching é um fenômeno comportamental que passa a ser difundido como a nova forma de se assistir, ou como o antropólogo cultural Grant 
McCracken, no seu estudo sobre o perfil do espectador que entra nesse processo, em conjunto com o Netflix: "mas esse espectador de TV é diferente, a batata do sofá acordou. E agora que os serviços, como o Netflix, deram aos consumidores o controle sobre o assistir TV, eles declararam uma nova forma de assistir "(Netflix, 2013).

Ainda dentro dos estudos divulgados pelo Netflix, algumas séries são mais "devoráveis" enquanto outras são mais "saboreáveis", conforme analisado pelo banco de dados dos assinantes do serviço em mais de 190 países, com acesso a mais de 100 séries. Foram analisados somente o perfil de usuários que assistiram uma temporada completa, com uma média global de 5 dias para se completar uma temporada. Em média geral, foram assistidas duas horas e 10 minutos das séries, sendo que as séries classificadas como "saboreáveis" foram consumidas por menos de duas horas por dia. Já as séries classificadas como "devoráveis", tiveram uma média maior que duas horas por dia. É válido salientar que os gêneros Suspense e Terror provocam um engajamento mais compulsivo do que os demais (Netflix, 2016).

Desses argumentos, se conclui que o binge watching está ligado a um comportamento ativo dos espectadores imersos por horas, se dedicando a um mesmo show com características textuais cult, em várias plataformas, em um universo de conteúdo, ultrapassando muito mais do que as horas dos dois a seis episódios. Há todo um novo processo industrial de geração de conteúdo voltado para essa audiência, cada dia mais ampla e dominante, tanto no desenvolvimento de roteiros mais complexos do que simplesmente uma narrativa seriada em episódios, que iam ao ar com uma periodicidade de acordo com a grade da programação da TV, quanto no meio de distribuição, e na concepção da narrativa e da publicidade que eventualmente a entrecorta.

\section{DESENVOLVIMENTO DE ROTEIROS PARA ESPECTADORES POTENCIALMENTE COMPULSIVOS}

O tratamento do conteúdo das séries de binge watching deixa de ser somente o processo narrativo que se desenrola na tela, seja pelas maratonas proporcionadas pelos canais convencionais de broadcast, seja pela facilidade de acesso pelos serviços de VOD, e passa a ser também um universo de conteúdo que permeia, joga, adiciona, intertextualiza informações para o espectador voraz. Quando abordamos os três pilares básicos que fomentam ou proporcionam o engajamento no consumo das séries, nos deparamos com a necessidade de um universo diegético que contribua para isso.

Esse universo de conteúdo é tratado como um texto audiovisual cult. Hills, parafraseado por Jenner, descreve três princípios básicos do texto cult:

o autor figura como um 'sujeito que supostamente sabe', uma narrativa sem fim, que quer dizer que o texto é marcado por certos enigmas e as resoluções desses vão sendo adiadas por muitas temporadas (e em alguns casos nem ocorre) e uma hiperdiegese, que significa um espaço narrativo vasto e detalhado, do qual somente uma fração é realmente vista ou encontrada dentro do texto, mas que de alguma forma parece operar de acordo com a lógica interna por completo. (Hills citado em Jenner, 2015, p. 10) 
As narrativas vão deixando de ser somente relacionadas ao meio tecnológico e passam a ser transmidiáticas ${ }^{2}$, seja na construção oficial de conteúdo fora da tela ou na relação ativista dos fandoms. A complexidade das narrativas com mundos externos à tela é um convite para se devorar o conteúdo quase instantaneamente. Esse universo semiótico que está, muitas das vezes, além da estrutura narratológica aparente e da trama apresentada na série, começa a criar o espectador participante do processo de significação. Will Brooker aprofunda essa discussão:

ao mesmo tempo que as narrativas vão se tornando cada vez mais transmedia, envolventes em mundos imersivos e desafios além dos limites da tela, elas se tornam uma questão de assistir e discutir de forma coletiva, mais do que um engajamento individual, mas essas narrativas acabam também, a apagar as fronteiras entre espectadores e participantes. (Brooker, 2009, p. 10)

A base de quase todos os projetos audiovisuais de ficção é uma história desenvolvida em um argumento e, em seguida, em um roteiro permeado com uma gama de possibilidades e considerações de diversos profissionais e situações, que aqui chamamos de desenvolvimento de roteiro (script development), e que muita das vezes é somente considerado como um diagrama, um esquema (blueprint) do objeto audiovisual finalizado, na tela. Da ideia até a tela há um conjunto variado e complexo de processos e pessoas, em um sistema de desenvolvimento em que autoria, desenvolvimento, produção, distribuição e consumo se entrelaçam em busca de um público.

Segundo o artigo “How Network TV Figured Out Binge-Watching - They're learning from Netflix":

as redes estão mudando a forma como desenvolvem e lançam seus novos shows, e até mesmo os comerciais, ao mesmo tempo que elas buscam se adaptar aos novos hábitos e lucros que o binge watching tornou popular pelos serviços de streaming como o Netflix. (Reuters, 2016, p. 1)

O processo de desenvolvimento do roteiro precisa lidar com um grande número de processos e etapas na cadeia de produção, como marketing, financiamento, produção, big data, receptor. Diversos princípios narratológicos e paradigmas de storytelling, atualmente brandidos como ferramentas de estruturação de roteiro, que funcionam nos formatos tradicionais de exibição, agora não servem plenamente como um guia para essas novas séries. A forma em que a história e os personagens principais e secundários são desenvolvidos precisa encontrar novos caminhos para poder ser atraente ainda depois de mais de dez horas com o espectador na mesma narrativa. Assim, o scrip development está sob uma mudança intensa quando se trata de criar séries com mais engajamento.

\footnotetext{
${ }^{2} \mathrm{O}$ conceito de transmídia definido por (Jenkins, 2011), "a narrativa transmidiática representa um processo onde elementos integrais de uma ficção são dispersos sistematicamente em múltiplos canais de veiculação, com o objetivo de criar uma experiência de entretenimento unificada e coordenada. Idealmente, cada mídia tem a sua contribuição própria única para o desenrolar da história".
} 
Um dos problemas centrais em um estudo sobre narratologia e binge watching é a complexidade pela forma como os elementos se relacionam, da linguística estruturalista ou pós-estruturalista da narratologia, em conjunto com a resposta de marketing de comportamento, reconhecido em dados recolhidos por algorítmos que determinam o modo em que diferentes tipos de conteúdos são consumidos. Diante das novas perspectivas de se consumir as séries dramáticas, seu formato passou a ser modificado, na forma da produção de conteúdo e de sua distribuição, com o lançamento de todos os episódios de uma temporada simultaneamente.

O escrutínio do modo de escrever e desenvolver, ou da forma como o diagrama (blueprint), o argumento e o roteiro possam se tornar o "texto" audiovisual já na tela, e a organização dos elementos, é de uma complexidade sistêmica contida nele mesmo:

certamente a prática de "desenvolvimento de história" e "desenvolvimento de argumento" são comumente usados como sinônimos, ou pelo menos, tratados como duas variantes do mesmo conceito. O largo uso da palavra "desenvolvimento" deveria ser entendido não como um encurtamento de "desenvolvimento de argumento", mas sim como um termo abrangente que aduz vários processos considerados necessarios para trazer à tela um argumento ou idea particular - um conhecimento prático que pode variar significantemente de redes, estúdios, colaborações e práticas individuais. Muito comumente o "desenvolvimento de um argumento" está ligado à imperativos de financiamento. (Taylor, 2015, p. 5)

O pilar principal do desenvolvimento do roteiro é a história a ser contada. No caso do audiovisual, isso implica em formatos e estruturas da escrita profissional e, no caso das séries viciantes, alguns aspectos começam a se delinear, tanto pela tentativa e erro, quanto por observações científicas na busca pelo engajamento.

As estruturas narrativas começaram a ter novos parâmetros. Perks (2014) analisa os perfis de personagens que estão presentes nas narrativas que provocam a compulsão, como por exemplo o Vilão Tecnocrata, o Herói improvável, O Titereiro, entre outras, e demonstra que há elementos na organização da trama que podem estar contribuindo para o engajamento, assim como existem alguns tipos de narrativas que mais provocam esse engajamento.

As séries, até então feitas para serem transmitidas exclusivamente uma vez por semana, em um determinado dia e horário com interrupções comerciais, mantinham alguns elementos de configuração no seu texto que foram constituídos no decorrer da história do entretenimento audiovisual: as séries episódicas ou procedurais. Comparato (1998) sugere a série ou a mini-série como uma história fechada a cada semana, a cada episódio, com início, meio e fim, e com uma macro estrutura. Ele explicita a necessidade de redundância na estrutura da narrativa para que o telespectador não perca no processo de consumo algum elemento passado.

A partir do momento que as séries passam a ser produzidas para serem disponibilizadas todos os episódios de uma só vez por temporada, os criadores podem trabalhar 
direto em todos os episódios, permitindo conceber como uma série, e não somente como um piloto. Os criadores da série do Netflix Bloodline, descreveram para o site Quartz alguns tópicos que nortearam a construção das estruturas narrativas viciantes de acordo com o seu último trabalho. A seguir parafraseamos alguns desses tópicos, sem aprofundá-los:

- no lugar de focar em episódios individuais, pense em toda a temporada como uma história cheia de camadas, com três atos;

- prenda a audiência desde o início, terminando os primeiros episódios com cliffhangers;;

- não se preocupe em desenvolver todos os personagens de uma vez só;

- trabalhe no formato do episódio, mantendo as coisas interessantes;

- não há necessidade de se repetir o elemento chave em cada episódio (Lynch, 2015).

Se uma história é feita para ser consumida não mais em episódios isolados, "isso significa que os criadores estão tomando uma temporada como uma unidade, livre de se fazer cada episódio como uma história ou tema", como afirma James J. Weinman (Weinman, s.d.)

É interessante observar que essa possível liberdade na concepção de uma série em temporadas se aproxima à liberdade de criação adotada nas webséries independentes, quando o vídeo na internet começou a se disseminar, principalmente com o YouTube. $O$ processo interativo de criação, não mais em contato com episódios mas com temporadas inteiras, permite ao autor das séries tratar os personagens de acordo com a reação e feedback dos espectadores. "Mais do que em qualquer outro meio, as webséries permitem aos criadores receberem um feedback e interagir com seus espectadores quase instantaneamente" (Williams, 2012, p. 143).

Com a natureza do meio de transmissão das séries pelos serviços de streaming, disposto e adaptado para a criação de universos de elementos das séries fora das horas assistidas, em conjunto com a constituição de comunidades sobre os temas e elementos das séries, e juntamente com uma narrativa tratada e desenvolvida para que esses elementos ocorram, vamos aos poucos construindo todo o sistema do binge watching.

O texto narrativo das séries viciantes permitem aos espectadores se engajarem e terem com isso um acesso mais rápido e fácil às memórias diegéticas da série, não gastando muita energia em lembrar de detalhes e podendo se aprofundar no mundo dos personagens. É assim que Perks descreve o gatilho para a satisfação do espectador, ou leitor como ela define, ao "maratonar" uma série de TV. Desse acesso a elementos da série nasce um relacionamento entre o espectador e os personagens. Uma relação para-social, em que o indivíduo se transporta para dentro do mundo da história, com os dilemas morais e aventuras do mundo da história:

essa relação positiva entre maratonar e interação parassocial é uma das conexões imersivas que ativam os personagens como pseudo-avatares. Esses

${ }_{3}$ Cliffhanger são elementos narrativos de grande suspense utilizados nas narrativas. 
pseudo-avatares não precisam com que o leitor tome as decisões, mas necessitam de um investimento efetivo do leitor para que aquelas decisões sejam relevantes. Mais do que formar uma relação parassocial tradicional que é escrita como uma pseudo-amizadae, a conexão imersiva era tão forte para os maratonistas que eles viajavam junto com seus personagens, encontrando suas vicissitudes com um investimento emocional e impacto maior do que de um membro do mundo da história faria.(Perks, 2014, p. 85)

Um outro elemento que pode contribuir e provocar o engajamento do espectador nas séries é a forma como as séries e as histórias são montadas, conforme citam Robert Kubey e Mihaly Csikszentmihalyi sobre as respostas orientadas ${ }^{4}$ : ao observar como nossas ondas cerebrais são afetadas pelos aspectos formais, os pesquisadores concluíram que esses truques estilístico podem de fato desencadear respostas involuntárias e "derivar o valor de atenção através da significação de detecção de movimento. (...) É a forma, não o conteúdo, da televisão que é única" (Kubey \& Csikszentmihalyi, 2002).

As séries feitas para serem viciantes, como House of Cards, permitem um desenvolvimento muito mais sofisticado da narrativa, como atesta o roteirista chefe Beau Willimo: "você não precisa se entregar e se avaliar semana a semana. Você nem precisa pensar nisso como televisão. E nenhum de nós pensou. Para nós era um filme de 13 horas" (Romano, 2013).

\section{Conclusão}

A compulsão de consumo de conteúdo em uma mídia não é algo totalmente atual, pois é um fenômeno cultural conhecido e estudado mesmo antes do advento da televisão pela internet. As organizações em fandoms, as trocas de fitas, DVDs e arquivos torrent ao longo das últimas décadas têm provocado o consumo de conteúdos audiovisuais por muitas horas seguidas, sem interrupção. No entanto, a televisão pela internet permitiu que esse fenômeno se propagasse e difundisse, se tornando uma das principais formas de audiência de séries e minisséries televisivas.

A questão tecnológica, ou melhor, o acesso disseminado às novas tecnologias, teria sido o primeiro passo para que o binge watching se popularizasse e deixasse de ser um comportamento de nicho. A possiblidade de acesso facilitado a informações adicionais, tanto para os fãs quanto para os espectadores mais passivos, seja para saciar a curiosidade de elementos da série ou para a troca de informações sobre o que se assiste, construindo o tempo fora da tela, é um dos elementos que caracterizam o maratonista de media da atualidade. Não seria somente o acesso ao meio tecnológico ou pelo meio tecnológico, mas a capacidade de se conviver ao redor do que a série propõe como universo diegético. Esse comportamento é mais fácil de difundir pela própria natureza da internet, com suas comunidades e sites mundiais sobre uma série e também com lançamento mundial simultâneo do conteúdo para diversos mercados.

${ }_{4}^{4}$ Respostas orientadas são as reações instintivas visuais ou sonoras a qualquer movimento, estudadas primeiramente por Pavlov em 1927. 
A possibilidade de acessos simultâneos com grupos geograficamente esparsos aumentaria a possibilidade de se engajar, pela capacidade dos espectadores encontrarem ressonância dos seus interesses com facilidade na internet, pela profusão em escala daquilo que os faz engajar. Daí o caráter mundial do Netflix ser um dos principais difusores do binge watching com sucesso mundial, e desse preparar a mensagem, ou melhor, as séries para fomentar esse tipo de consumidor.

É no formato do conteúdo, nesse tratamento da mensagem, que residem as principais características do binge watching. A liberdade de acesso ao conteúdo, que a popularização do vídeo pela web permitiu ao espectador, abriu a possibilidade de novas formas de criação de entretenimento.

A profissionalização desse entretenimento, se apropriando da maturidade de negócio que a televisão desenvolveu ao longo dos anos, permite com que o binge watching seja considerado a nova forma dominante de se ver TV. Apesar da imprensa às vezes difundir que as séries viciantes não se pareçam com televisão, elas são exatamente a renovação ou a profissionalização que a web trouxe para o meio.

Ao alinhar a capacidade tecnológica de distribuição da internet, sem limite de horário e local, com a liberdade de escolha do espectador, sobre o que quer assistir e como assistir, e o tratamento da dramaticidade das séries, tornando as temporadas em longas metragens de várias horas, a televisão pela internet passou a entregar o produto na forma que os espectadores esperariam consumir, para ser devorada em horas pela internet e na internet, nos mais diferentes formatos de tela, como a televisão e os monitores de computador, dos smartphones e tablets.

Essa mudança no tratamento das séries, com a quebra da narrativa com histórias completas em vários episódios, como sugere os autores de Bloodline, ou como observamos nas temporadas do Netflix, nos proporciona uma nova forma de produção e consumo das séries televisivas. Não somente a complexidade da narrativa, mas a quebra da estrutura entrecordada da mesma, que antes acontecia pelos blocos de minutos para inserção da publicidade, o fim do episódio como uma unidade completa em si, e das séries procedurais, vai surgindo como o novo paradigma de estruturação para a televisão. As séries viciantes não são o fim da televisão, mas a forma como esse meio está se apropriando da internet para criar seus modelos de entretenimento e negócio, assim como aconteceu com a criação da tv a cabo ou por assinatura. As séries viciantes são o formato narrativo sugerido para esse meio de distribuição.

Alguns padrões começam a surgir, diante desse cenário, quanto à forma de tratamento da trama, dos personagens e do tempo ou ritmo narrativo. A estruturação das séries e a narratologia dos elementos televisivos, adaptados à liberdade de significação pelo espectador da história, contada como um grande filme de mais de dez horas, com universos paralelos, como em fases de um jogo, com elementos fora da tela principal, são exemplos na construção dessa nova e popular forma de se contar uma história. 


\section{FinANCIAMENTO}

Esse trabalho teve o apoio financeiro do Conselho de Desenvolvimento Científico e Tecnológico (CNPq) e do Programa de Pesquisa e Iniciação Científica da Universidade FUMEC (ProPIC/FUMEC).

\section{REFERÊNCIAS BIBLIOGRÁFICAS}

@actheseries (s.d.). Artistically Challenged (@actheseries). Fotos e vídeos do Instagram. Retirado de https://www.instagram.com/actheseries/

Brooker, W. (2009). Television out of time: Watching cult shows on download. Reading Lost: Perspectives on a Hit Television Show. Retirado de http://web.mit.edu/uricchio/Public/television/brooker online viewing.pdf

Comparato, D. (2009). Da criação ao roteiro: edição revista e atualizada, com exercícios práticos. São Paulo: Editora Summus.

DigitalTV Europe (2014). Netflix boss predicts the end of broadcast TV Digital TV Europe. Retirado de http:// www.digitaltveurope.net/285582/netflix-boss-predicts-the-end-of-broadcast-tv/

Grenouille (2004). Après le haut débit, l'internet ultra-rapide débarque en Europe. Retirado de http://forums. grenouille.com/index.php?s=3ddg8f22fdbca44booa2c961bf635fc6\&showtopic $=22845$

Huffingtonpost (2015). Internet Television - an Anniversary | HuffPost. Retirado de http://www. huffingtonpost.com/victor-dorff/internet-and-television-o_b_8602316.html

Jenkins, H. (2011). Transmedia 202: Further Reflections. Retirado de http://henryjenkins.org/2011/08/ defining_transmedia_further_re.html

Jenkins, H. (2012). Textual poachers: Television fans and participatory culture. Londres: Routledge.

Jenner, M. (2015). Binge-watching: Video-on-demand, quality TV and mainstreaming fandom. International Journal of Cultural Studies, 6(1), 64-81. Retirado de http://journals.sagepub.com/doi/ abs/10.1177/1367877915606485

Kubey, R. \& Csikszentmihalyi, M. (2002). Television addiction. Scientific American, 286(2), 74-81. Retirado de http://sites.oxy.edu/clint/physio/article/televisionaddiction.pdf

Lynch, J. (2015). Here's the recipe Netflix uses to make binge-worthy TV - Quartz. Retirado de https:// qz.com/367117/heres-the-recipe-netflix-uses-to-make-binge-worthy-tv/

Nakamura, H. (2015). Inside SET EXPO 2015 entrevista Hiroshi Nakamura, Gerente de Fibra Ótica FURUKAWA//Japão. Vídeo YouTube. Retirado de https://www.youtube.com/watch?v=IIdDwQd_uoY

Netflix (2013). Netflix Declares Binge Watching is the New Normal. Retirado de https://media.netflix.com/ en/press-releases/netflix-declares-binge-watching-is-the-new-normal-migration-1

Netflix (2016). A Netflix e as maratonas: novo gráfico de maratonas revela as séries que são devoradas e as que são saboreadas. Retirado de https://media.netflix.com/pt_br/press-releases/ netflix-binge-new-binge-scale-reveals-tv-series-we-devour-and-those-we-savor-1

Netflix (2017). About Netflix. Retirado de https://media.netflix.com/en/about-netflix

Perks, L. (2014). Media marathoning: Immersions in morality. Lanham, Maryland: Lexington Books. 
Reuters (2016). How network TV figured out binge-eatching. Retirado de http://fortune.com/2016/03/11/ netflix-changing-game-network-tv/

Romano, A. (2013, 5 de maio). The way they hook us - for 13 hours straight. Newsweek. Retirado de http:// www.andrewromano.net/40/the-way-they-hook-us-for-13-hours-straight

Taylor, S. (2015). "It's the Wild West out there": Can web series destabilise traditional notions of script development? In ASPERA Annual Conference 2015: What's This Space (pp. 1-14). Retirado de https:// researchbank.rmit.edu.au/view/rmit:34639

Weinman, J. (s.d.). The stand-alone episode meets its end. Retirado de http://www.macleans.ca/culture/ television/the-stand-alone-episode-meets-its-end/

Williams, D. (2012). Web TV series: how to make and market them. Harpenden: Oldcastle Books.

Wolff, M. (2015). Televisão é a nova televisão. São Paulo: Globo Editora.

\section{NOTAS BIOGRÁFICAS}

Humberto de Campos Rezende, mestrando em Estudos Culturais Contemporâneos pela FUMEC. Graduado em Comunicação, com experiência na área de Artes e Negócios com ênfase em Administração e Produção de Filmes e programas para TV, Cinema e Internet. Tem experiência como administrador de marcas, produtos e imagens de produtos, personalidades e personagens ligadas ao audiovisual.

E-mail: humbertocr@coruba.com.br

Rua João XXIII, 13, Centro - Ritápolis, Minas Gerais, Brasil - CEP 36335-000

João Victor Boechat Gomide é Doutor em Artes e Doutor em Física. Desenvolve produções e investigações em diferentes áreas da produção audiovisual. É autor do livro Imagem Digital Aplicada, pela Editora Elsevier/Campus. Coordena o Bacharelado em Computação Gráfica e o Curso Superior de Tecnologia em Jogos Digitais da Universidade FUMEC.

E-mail: jvictor@fumec.br

Universidade FUMEC/FACE

Rua Cobre, 200 - Cruzeiro - CEP 30.310-190 - Belo Horizonte, Minas Gerais - Brasil

* Submetido: 04/03/2017

* Aceite: 08/05/2017 